\title{
FONTES DE NITROGÊNIO E DOSES DE CLORETO DE POTÁSSIO NA CULTURA DO ABACAXI PÉROLA
}

Simone Guedes da Silva ${ }^{1}$; Edinéia Zulian Dalbosco ${ }^{2}$; Dhiego Pereira Krause ${ }^{3}$; Willian Krause $^{4}$; Adalberto Santi ${ }^{5}$

1. Engenheira Agrônoma pela Universidade do Estado de Mato Grosso, Tangará da Serra-MT, Brasil.

2. Pós-graduanda em Genética e Melhoramento de Plantas pela Universidade do

Estado de Mato Grosso, Tangará da Serra-MT, Brasil. E-mail: zulian_edineia@hotmail.com

3. Graduando em Ciências Biológicas da Universidade do Estado de Mato Grosso, Tangará da Serra-MT, Brasil.

4. Professor Doutor em Genética e Melhoramento de Plantas do programa de pósgraduação em Genética e Melhoramento de Plantas da Universidade do Estado de Mato Grosso, Tangará da Serra-MT, Brasil.

5. Professor Doutor em Agricultura Tropical da Universidade do Estado de Mato Grosso, Tangará da Serra-MT, Brasil.

Recebido em: 01/07/2015 - Aprovado em: 31/07/2015 - Publicado em: 21/08/2015

\section{RESUMO}

A adubação tem influência diretamente sobre a produtividade e qualidade dos frutos do abacaxizeiro podendo ser um fator limitante para produção. Desta forma, o objetivo do trabalho foi identificar a melhor fonte de nitrogênio e a dose de cloreto de potássio recomendado para a cultura do abacaxi Pérola na região de Tangará da Serra. O experimento foi conduzido na área experimental da Universidade do Estado de Mato Grosso, sendo o solo classificado como Latossolo Vermelho Distroférrico, de textura argilosa e de relevo plano à levemente ondulado. $O$ delineamento experimental foi em blocos casualizados, com a cultivar Pérola, num arranjo fatorial $5 \times 2$, sendo cinco doses de cloreto de potássio $\left(0,350,700,1050\right.$ e $\left.1400 \mathrm{~kg} \mathrm{ha}^{-1}\right)$ e duas fontes de Nitrogênio (600 kg ha-1 de ureia e $1350 \mathrm{~kg} \mathrm{ha}^{-1}$ de sulfato de amônio), com quatro repetições. Foram avaliadas cinco características físicas e o sólido solúvel total. O uso do sulfato de amônio como fonte de adubação nitrogenada proporcionou frutos maiores em relação ao uso da ureia. A adubação potássica na dose $876,98 \mathrm{~kg} \mathrm{ha}^{-1}$ conferiu uma produtividade de $30.840 \mathrm{~kg}$ de frutos ha-1 e a dose de $1268,83 \mathrm{~kg} \mathrm{ha}^{-1}$ propiciou 27.965 frutos ha-1.

PALAVRAS-CHAVE: Adubação, efeito, latossolo, qualidade, produtividade.

\section{NITROGEN SOURCES AND POTASSIUM CHLORIDE DOSES IN CULTURE OF "PÉROLA" PINEAPPLE}

\begin{abstract}
The fertilization influences directly on productivity and fruit quality of pineapple and it can be a limiting factor for production. Thus, the goal of the research was to identify the best nitrogen source and the dose of potassium chloride recommended for a "Pérola" pineapple crop in Tangara da Serra. The experiment was conducted in the experimental area of the University of the State of Mato Grosso, which soil is
\end{abstract}


classified as Dystrophic Red Latosol of clayey texture and plan to slightly wavy. The experimental design was a randomized block, with the cultivar Pearl, in a $5 \times 2$ factorial arrangement, with five doses of potassium chloride $(0,350,700,1050$ and $\left.1400 \mathrm{~kg} \mathrm{ha}^{-1}\right)$ and two sources of nitrogen $\left(600 \mathrm{~kg} \mathrm{ha}^{-1}\right.$ of urea and $1350 \mathrm{~kg} \mathrm{ha}^{-1}$ of ammonium sulfate) with four replications. Five physical characteristics and the total soluble solid were evaluated. The use of ammonium sulfate as nitrogen fertilizer source provided greater fruits in relation to the use of urea. Potassium fertilization dose $876.98 \mathrm{~kg} \mathrm{ha}^{-1}$ gave a productivity of $30,840 \mathrm{~kg}$ in fruits ha $\mathrm{ha}^{-1}$ and the dose of $1268.83 \mathrm{~kg} \mathrm{ha}^{-1}$ led to 27,965 fruits $\mathrm{ha}^{-1}$.

KEYWORDS: fertilization, effect, oxisol, quality, productivity.

\section{INTRODUÇÃO}

O abacaxizeiro (Ananas comosus L. Merril) é uma monocotiledônea, originário de regiões tropicais e subtropicais, pertencente à família Bromeliácea. Tem grande aceitação de consumo em todo o mundo, podendo ser consumido in natura ou industrializado, por apresentar ótimo sabor e aroma intenso (CRESTANI et al., 2010).

O aumento significativo da produção nacional em relação à área cultivada é reflexo dos constantes aumentos da produtividade observados a cada ano, decorrentes das melhorias das condições de cultivo (FAOSTAT, 2015). Dados de 2013 apontam uma produção de 574.658 mil frutos, em 51.177 hectares e com rendimento médio de 26.199 frutos ha $^{-1}$. O Estado de Mato Grosso obteve uma produção de 7.140 mil frutos em 1.930 ha, com rendimento médio de 22.490 frutos ha $^{-1}$ (IBGE, 2015).

$\mathrm{Na}$ cultura do abacaxizeiro um dos fatores determinantes de melhorias na produtividade é a nutrição das plantas (SEMA et al., 2010). Quando os elementos químicos estiverem em baixa quantidade no solo ou o fornecimento por meio da adubação for insuficiente e/ou desbalanceada, isso afetará diretamente na produtividade e na qualidade do fruto.

A base da adubação são fontes de nitrogênio, fósforo e potássio. A ureia e o sulfato de amônio são as fontes de nitrogênio mais utilizadas, os benefícios estão na retenção de água, estrutura do solo, disponibilidade dos demais nutrientes e na microbiologia do solo (GUARÇONI \& VENTURA, 2011). A adubação nitrogenada, tanto referente à dose quanto à fonte, interfere no crescimento da planta determinado pelos componentes: diâmetro do caule, número de folhas emitidas, comprimento da folha "D" e, consequentemente, na massa dos frutos (CARDOSO et al., 2013).

O efeito positivo da adubação potássica sobre a qualidade e produtividade dos frutos de abacaxi está relacionado ao peso médio, comprimento e diâmetro do fruto, sendo que a deficiência reduz os sólidos solúveis totais (REIS et al., 2012). Apesar da importância socioeconômica do abacaxizeiro para as regiões produtoras, trabalhos sobre o desenvolvimento desta cultura nas condições edafoclimáticas no Cerrado Mato-grossense são escassos. Neste sentido, o objetivo deste trabalho foi identificar a melhor fonte de nitrogênio e a dose de cloreto de potássio recomendado para a cultura do abacaxizeiro no Estado de Mato Grosso.

\section{MATERIAL E MÉTODOS}

O experimento foi conduzido na área experimental da Universidade do Estado de Mato Grosso (UNEMAT), no Campus Universitário de Tangará da Serra - MT, 


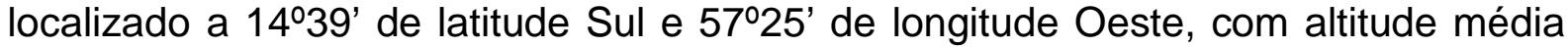
de 320 metros. O clima da região é tropical apresentando estação seca e chuvosa bem definida, a precipitação média anual varia de 1300 a $2000 \mathrm{~mm} \mathrm{ano}^{-1}$, com temperatura anual que varia entre 16 a $36^{\circ} \mathrm{C}$ (MARTIN S et al., 2010).

O solo classificado como latossolo vermelho distroférrico, de textura argilosa e de relevo plano à levemente ondulado (EMBRAPA, 2006). A análise química do solo realizada antes da instalação do experimento determinou os seguintes valores (Tabela 1).

TABELA 1: Característica química e física do solo, na área experimental.

\begin{tabular}{|c|c|c|c|c|c|c|c|c|c|c|c|c|}
\hline \multirow{2}{*}{ Solo } & $\mathrm{pH}$ & $\begin{array}{c}\mathrm{P} \\
\text { resina }\end{array}$ & $\mathrm{K}$ & $\mathrm{Ca}$ & $\mathrm{Mg}$ & $\mathrm{Al}$ & $\mathrm{H}+\mathrm{Al}$ & \multirow{2}{*}{$\begin{array}{l}\mathrm{V} \\
\%\end{array}$} & \multirow{2}{*}{$\begin{array}{c}\mathrm{MO} \\
\mathrm{gdm}^{-3}\end{array}$} & \multirow{2}{*}{\multicolumn{2}{|c|}{ Areia Silte }} & \multirow[t]{2}{*}{ Argila } \\
\hline & $\mathrm{CaCl}_{2}$ & ------- & 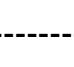 & $\mathrm{mn}$ & $\mathrm{m}$ & -- & ------- & & & & & \\
\hline & 4,7 & 6 & 0,8 & 14 & 7 & 2 & 46 & 29 & 40 & 256 & 183 & 561 \\
\hline
\end{tabular}

O delineamento foi em blocos casualizados no esquema fatorial $(5 \times 2)$, sendo cinco doses de cloreto de potássio e duas fontes de nitrogênio (sulfato de amônio e uréia) e quatro repetições. As doses de cloreto de potássio foram de $0,350,700$, 1050 e $1400 \mathrm{~kg} \mathrm{ha}^{-1} \mathrm{e}$ as fontes de $\mathrm{N}$ foram de $600 \mathrm{~kg} \mathrm{ha}^{-1}$ de uréia e $1.350 \mathrm{~kg} \mathrm{ha}^{-1}$ de sulfato de amônio de acordo com a recomendação da $5^{\text {a }}$ aproximação de Minas Gerais (RIBEIRO et al., 1999).

O espaçamento de plantio utilizado foi de $1,2 \times 0,4 \times 0,4$ metros, correspondente a uma população de 31.250 plantas ha ${ }^{-1}$. Cada parcela teve cinco fileiras duplas de quatro metros de comprimento, sendo que para as avaliações foram consideradas somente as três fileiras duplas centrais, num total de 60 plantas por parcela. De acordo com a análise do solo, a correção ocorreu 60 dias antes do plantio, a calagem foi fracionada entre a aração e a gradagem, visando elevar a saturação a $50 \%$. Para adubação de plantio foram aplicados nove $\mathrm{g}$ planta $^{-1}$ de monoamônio fosfato (MAP) no sulco.

As mudas utilizadas foram do tipo filhote, antes do plantio, as mudas foram separadas pelo tamanho em médio $(40$ a $50 \mathrm{~cm}$ ) e grande (maior que $50 \mathrm{~cm}$ ), da cultivar Pérola, o plantio ocorreu em novembro de 2009. No período da seca foi realizada irrigação por aspersão no intuito de manter o solo próximo à capacidade do campo.

A adubação de cobertura de ambas as fontes de $\mathrm{N}$ e as doses de cloreto de potássio foram parceladas em três aplicações, sendo 90, 120 e 150 dias após o plantio. A indução floral foi realizada 250 dias após o plantio, com a aplicação de Ethrel (ethephon) (50 mL planta $\left.{ }^{-1}\right)$ na forma líquida, colocado no centro da roseta foliar. Durante a condução do experimento foram realizadas as práticas culturais, visando garantir as condições de limpeza e de sanidade das plantas. Com intuito de proteger os frutos contra raios solares, durante o período de maturação foi necessário envolvê-los com papel jornal.

A colheita ocorreu aos 150 dias após a indução floral. Os frutos de cada parcela foram contados e pesados para estimar a produtividade em números de frutos ha ${ }^{-1}$ e em $\mathrm{kg} \mathrm{ha}^{-1}$, também foi determinada a massa de frutos em gramas. Aleatoriamente, foram selecionados 10 frutos de cada parcela e conduzido ao Laboratório de Melhoramento de Plantas e Sementes para a realização dos demais testes. Com auxílio de um paquímetro, foi determinado o comprimento do fruto (CF), sem coroa e o diâmetro dos frutos (DF). A análise química dos frutos para AGRARIAN ACADEMY, Centro Científico Conhecer - Goiânia, v.2, n.03; p. 642015 
determinar os sólidos solúveis totais (SS) foi utilizando um refratômetro portátil digital, as amostragens foram das regiões basal, mediana e apical dos frutos.

Os dados obtidos foram submetidos à análise de variância para cada característica avaliada. As médias dos tratamentos para as fontes de $\mathrm{N}$ foram comparadas pelo teste de Tukey ao nível de $5 \%$ de probabilidade. As doses de cloreto de potássio foram analisadas por meio do teste de regressão, utilizando-se o programa computacional SISVAR (FERREIRA, 2011).

\section{RESULTADOS E DISCUSSÃO}

$\mathrm{Na}$ avaliação das fontes de nitrogênio, observou-se diferença significativa para as características: massa do fruto (MF), número de fruto (NF) e diâmetro de fruto (DF). O sulfato de amônio proporcionou frutos com maior massa, comprimento e diâmetro (Tabela 2). Isto ocorreu devido a composição do sulfato de amônio proporcionar a recuperação de nitrogênio mais eficientemente do que a ureia (VILLAS BÔAS et al., 2005). A constituição do sulfato de amônio é de $20 \%$ de nitrogênio $(N)$ e $23 \%$ de enxofre (S) solúvel em água, cristalizado e pouco hidroscópico, razão por que os grânulos são revestidos com material protetor para diminuir a higroscopicidade. Já a ureia é composta de $45 \%$ de nitrogênio $(\mathrm{N})$ solúvel em água e absorve com facilidade a umidade do ar (higroscopicidade). Esses resultados foram similares aos encontrados por SPIRONELLO et al. (2004), quando o sulfato de amônio proporcionou acréscimo na produtividade, massa, diâmetro e comprimento de fruto. De acordo com CAETANO et al. (2013), as características comprimento e o diâmetro do fruto apresentam correlação positiva com a massa do fruto.

Com relação as normas de classificação do abacaxi (CEAGESP, 2015) e o padrão de comercialização de frutos que varia de 1.000 a $1.500 \mathrm{~g}$ (PEREIRA et al., 2009), tanto o sulfato de amônio como a uréia propiciaram massa de frutos adequados (Tabela 2).

TABELA 2: Médias das fontes de $\mathrm{N}$ para as características avaliadas: Produtividade (PROD), massa de fruto (MF), número de fruto (NF), comprimento do fruto (CF), diâmetro do fruto (DF) e sólidos solúveis totais (SS).

Características Avaliadas

\begin{tabular}{|c|c|c|c|c|c|c|}
\hline Fonte de $\mathrm{N}$ & $\begin{array}{c}\text { PROD } \\
\left(\mathrm{kg} \mathrm{ha}^{-1}\right)\end{array}$ & $\begin{array}{l}\text { MF } \\
(\mathrm{g})\end{array}$ & $\begin{array}{l}\text { NF } \\
\text { (un) }\end{array}$ & $\begin{array}{l}\mathrm{CF} \\
(\mathrm{cm})\end{array}$ & $\begin{array}{c}\text { DF } \\
(\mathrm{cm})\end{array}$ & 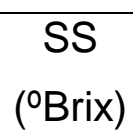 \\
\hline Sulfato de & $29.631,9 a^{1 /}$ & $1.132,6 a$ & $26.041,7 a$ & $14,3 a$ & $10,9 a$ & $13,3 a$ \\
\hline Ureia & $28.900,1 a$ & $1.063,9 b$ & $27.231,5 a$ & $13,9 b$ & $10,6 b$ & $13,4 a$ \\
\hline
\end{tabular}

${ }^{1 /}$ Médias seguidas de mesma letra não diferem estatisticamente entre si pelo teste de Tukey, a 5\% de probabilidade.

Com relação as doses de cloreto de potássio, verificou-se diferença significativa para as caraterísticas produtividade, número de frutos e sólidos solúveis totais. A característica produtividade apresentou efeito quadrático, sendo que a dose do ponto de máxima foi de $876,98 \mathrm{~kg} \mathrm{ha}^{-1}$ de cloreto de potássio e obteve produtividade de $30.840 \mathrm{~kg} \mathrm{ha}^{-1}$ de frutos (Figura 1). O cloreto de potássio, fertilizante mineral, contém $60 \%$ de $\mathrm{K}_{2} \mathrm{O}$ na formulação, é responsável pelo carregamento da sacarose no floema e, assim, na taxa de transporte dos 
fotoassimilados da fonte para 0 dreno. A falta deste elemento afeta consideravelmente o desenvolvimento, crescimento e frutificação das plantas (REIS et al., 2012).

REIS et al. (2012), em Cassilândia (MS), ao avaliarem a cultivar Pérola manejada com adubação potássica obtiveram produtividade de $50.416 \mathrm{~kg} \mathrm{ha}^{-1} \mathrm{na}$ dose de $200 \mathrm{~kg} \mathrm{ha}^{-1}$. Esta diferença pode ser atribuída a diferença de $\mathrm{K}_{2} \mathrm{O}$ no solo. Enquanto que o solo de Tangará da Serra-MT apresentou baixo teor de $\mathrm{K}_{2} \mathrm{O}(0,8$ $\mathrm{mmol}_{c} \mathrm{dm}^{-3}$ ), em Cassilândia-MS o teor foi de $1 \mathrm{mmol}_{c} \mathrm{dm}^{-3}$.

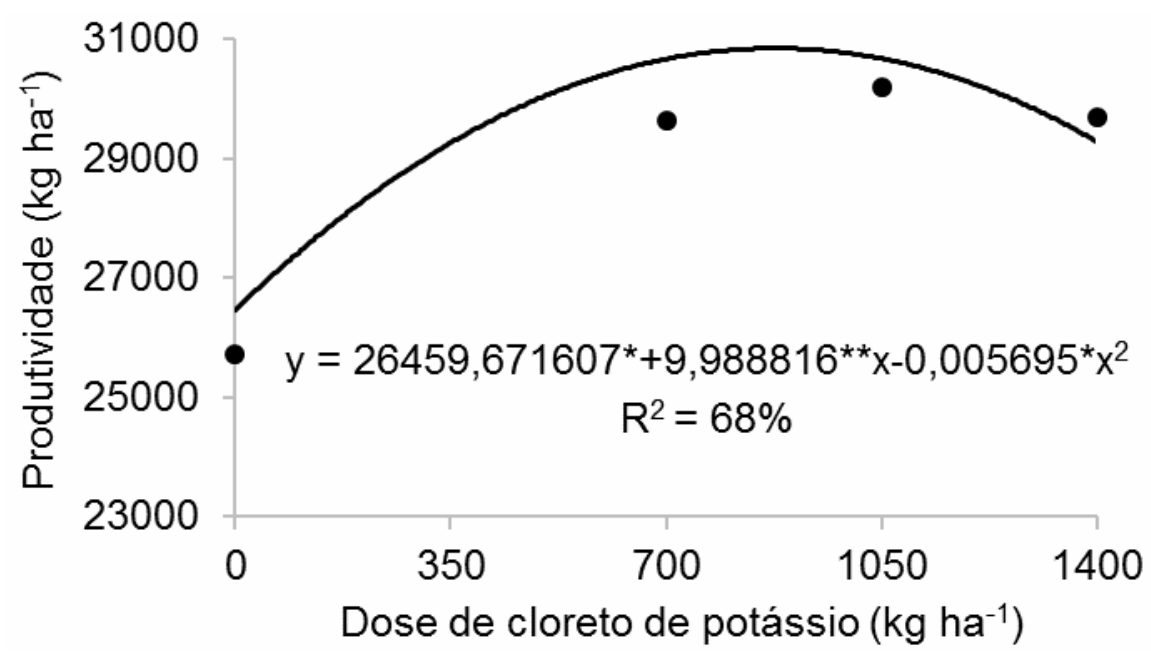

FIGURA 1: Efeito de doses de cloreto de potássio sobre a produtividade. Tangará da Serra - MT.

FONTE: SILVA et al., 2015.

Para o número de frutos houve efeito linear, onde a dose de $1268,83 \mathrm{~kg} \mathrm{ha}^{-1}$ de cloreto de potássio proporcionou 27.965 frutos ha ${ }^{-1}$ (Figura 2).

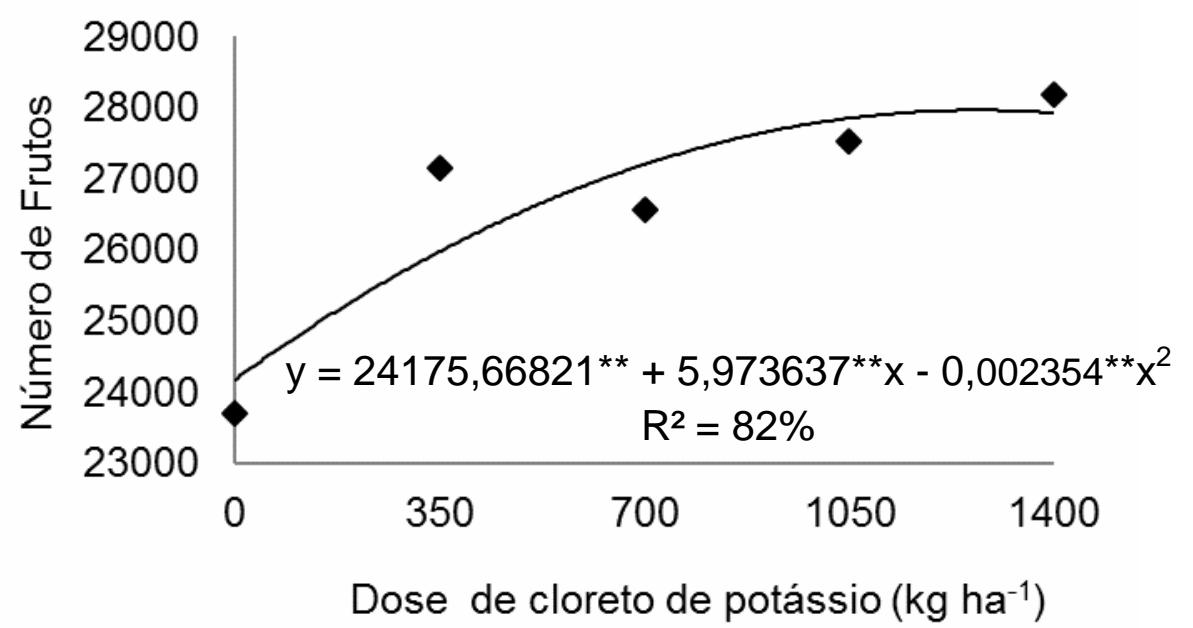

FIGURA 2: Efeito das doses de cloreto de potássio sobre o número de frutos.

FONTE: SILVA et al., 2015

$\mathrm{Na}$ análise da característica sólido solúvel total, ocorreu efeito quadrático da adubação potássica nos frutos do abacaxizeiro. O ponto de máxima na dose de 
cloreto de potássio foi de 906,75 $\mathrm{kg} \mathrm{ha}^{-1}$, foi obtido 14,15 Brix (Figura 3). A adubação potássica exerce influência acentuada na composição química, principalmente no sólido solúvel total (SILVA et al., 2015).

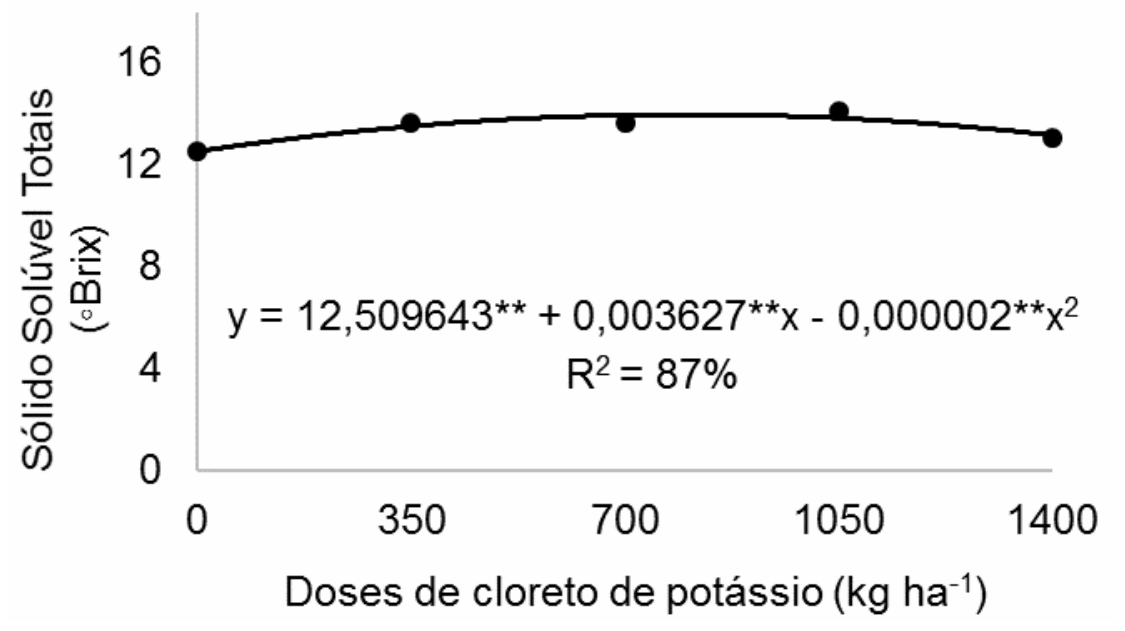

FIGURA 3: Efeito das doses de cloreto de potássio sobre sólidos solúveis totais.

FONTE: SILVA et al., 2015.

CHAVES et al. (2011), ao avaliarem a cultivar Pérola obtiveram variações entre 7 a 14 Brix. BERILLI et al. (2011), ao analisarem diferentes cultivares de abacaxizeiro, encontraram para sólido solúvel total na cultivar Pérola 13,07 B Brix, sendo inferior aos resultados encontrados neste trabalho. Valores acima de 12 Brix são aceitáveis pelos consumidores brasileiros e, principalmente, pelo mercado europeu (SILVA et al., 2007).

A adubação deve ser realizada de acordo com a análise do solo. NASCENTE et al. (2005), no estado de Rondônia recomendam aplicação de $711,11 \mathrm{~kg} \mathrm{ha}^{-1}$ de cloreto de potássio, para OLIVEIRA et al. (2006) a adubação potássica em abacaxizeiro no Extremo Sul da Bahia é a mesma dosagem, esses resultados corroboram com os dados encontrados deste trabalho no Estado de Mato Grosso.

$O$ déficit de nutriente no solo em determinadas regiões e a exigência nutricional da cultura do abacaxizeiro, torna-se necessário complementar com parcelamento de adubação, visando o aumento da produtividade e melhorar a qualidade do fruto. No entanto, há poucas informações sobre o efeito da adubação obtidas no abacaxizeiro, especialmente sob condições tropicais (AMORIM et al., 2013).

\section{CONCLUSÕES}

O uso do sulfato de amônio como fonte de adubação nitrogenada proporcionou frutos maiores em relação ao uso da ureia. A adubação potássica na dose $876,98 \mathrm{~kg} \mathrm{ha}^{-1}$ conferiu uma produtividade de $30.840 \mathrm{~kg}$ de frutos ha $\mathrm{ha}^{-1} \mathrm{e}$ a dose de $1268,83 \mathrm{~kg} \mathrm{ha}^{-1}$ propiciou 27.965 frutos $\mathrm{ha}^{-1}$.

\section{AGRADECIMENTOS}

Ao Conselho Nacional de Desenvolvimento Científico e Tecnológico (CNPq) e a Fundação de Amparo à Pesquisa do Mato Grosso (FAPEMAT) pelo suporte financeiro. 


\section{REFERÊNCIAS}

AMORIM, A.; GARRUTI, D.; LACERDA, C.; MOURA, C.; GOMES-FILHO, E. Postharvest and sensory quality of pineapples grown under micronutrients doses and two types of mulching. African Journal of Agricultural Research, Lagos, v. 8, n.19, p.2240-2248, 2013.

BERILLI. S. da S.; ALMEIDA, S. B.; CARVALHO. A. J. C. de; FREITAS. S. de J. BERILLI, A. P. C. G.; SANTOS; P. C. dos. Avaliação sensorial dos frutos de cultivares de abacaxi para consumo in natura. Revista Brasileira de Fruticultura, Jaboticabal - SP, Volume Especial, E. 592-598, 2011.

CAETANO. L. C. S.; VENTURA. J. A.; COSTA. A. de F. S. da; GUARÇONI. R. C. Efeito da adubação com nitrogênio, fósforo e potássio no desenvolvimento, na produção e na qualidade de frutos do abacaxi 'vitória'. Revista Brasileira de Fruticultura, Jaboticabal - SP, v. 35, n. 3, p. 883-890, 2013.

CARDOSO, M. M.; PEGORARO, R. F.; MAIA, V. M.; KONDO, M. K.; FERNANDES, L. A. Crescimento do abacaxizeiro 'vitória' irrigado sob diferentes densidades populacionais, fontes e doses de nitrogênio. Revista Brasileira de Fruticultura, Jaboticabal - SP, v. 35, n. 3, p. 769-781, Setembro 2013.

CEAGESP. Programa brasileiro para modernização da horticultura: normas de classificação do abacaxi. São Paulo: Central de Qualidade em Horticultura, 2015. (Documentos, 24).

CHAVES, K. F.; CRUZ, W. F. DA; SILVA. V. R. O.; MARTINS, A. D. DE O.; RAMOS. A. DE L. S.; SILVA, M. H. L. Características físico-químicas e aceitação sensorial de abacaxi 'Pérola' minimamente processado adicionado com antioxidantes. Tecnologia \& Ciência Agropecuária, João Pessoa, v. 5, n. 1, p. 35-39, mar/ 2011.

CRESTANI, M.; BARBIERI, R. L.; HAWERROTH, F. J. Das Américas para o Mundo - origem, domesticação e dispersão do abacaxizeiro. Ciência Rural, Santa Maria. v. 40, n. 6, 2010.

EMPRESA BRASILEIRA DE PESQUISA AGROPECUÁRIA (BRASIL). Sistema brasileiro de classificação de solo. 2 ed. Rio de Janeiro: EMBRAPA Solos, 2006. 306p.

FAOSTAT - Food and Agriculture Organization of the United Nations Statistical Database. Crops database. Disponível em: <http:// faostat.fao.org/site/567/DesktopDefault.aspx?PagelD=567\#ancor>. Online. Acesso em: 26 abr. 2015.

FERREIRA, D.F. SISVAR: a computer statistical analysis system. Ciência Agrotecnologia, Lavras, v. 35, n. 6, p. 1039-1042, 2011. 
GUARÇONI, M. A.; VENTURA. J. A. Adubação n-p-k e o desenvolvimento, produtividade e qualidade dos frutos do abacaxi 'Gold' (MD-2). Revista Brasileira Ciência do Solo, n. 35, p. 1367-1376, 2011.

IBGE - Instituto Brasileiro de Geografia e Estatística. Quantidade produzida, valor da produção, área plantada e área colhida da lavoura permanente no ano de 2013. Disponível em: <http://www.sidra.ibge.gov.br>. Acesso em: 25 de janeiro de 2015.

MARTINS, J. A.; DALLACORT, R.; INOUE, M. H.; SANTI, A.; KOLLING, E. M.; COLETTI, A. J. Probabilidade de precipitação para a microrregião de Tangará da Serra, Estado do Mato Grosso. Pesquisa Agropecuária Tropical, v. 40, p.291-296, 2010.

NASCENTE, A. S.; COSTA, R. S. C DA; COSTA, J. N. M. Sistema de produção. Cultivo do abacaxi em Rondônia. http://sistemasdeproducao.cnptia.embrapa.br /FontesHTML/Abacaxi/CultivodoAbacaxiRO/adubacao.htm. Online. Acesso em: 21 jul. 2015.

OLIVEIRA, A. M. G. de; SOUZA, L. F. da S.; CABRAL, J. R. S.; COUTINHO, S. da C.; BENFICA, A. F. Recomendação de adubação para abacaxi Pérola não irrigado em municípios do Extremo Sul da Bahia: 1a aproximação. In: Reunião brasileira de fertilidade do solo e nutrição de plantas, 27, 2006, Bonito. Anais... Bonito: SBCS: SBM: Embrapa Agropecuária Oeste, p.1-4, 2006.

PEREIRA, M.A.B.; SIEBENEICHLER, S.C.; LORENÇONI, R.; ADORINA, G.C.; SILVA, J.C.; GARCIA, R.B.M.; PEQUENO, D.N.L.; SOUZA, C.M.; BRITO, R.F.F. Qualidade do fruto de abacaxi comercializado pela Cooperfruto - Miranorte TO. Revista Brasileira de Fruticultura, Jaboticabal, v. 31, n. 4, p. 1048-1053, dez./ 2009.

REIS. L. L. dos; TARSITANO. M. A. A.; HIRAKI. S. S.; BARDIVIESSO, D. M. Custo de produção e rentabilidade de abacaxizeiro cv. Pérola em cassilândia (ms), sob diferentes doses de potássio. Journal Biosciense, Uberlândia, v. 28, n. 5, p. 725733, 2012.

RIBEIRO, A.C.; GUIMARÃES, P.T.G.; ALVAREZ, V.H. Recomendações para o uso de corretivos e fertilizantes em Minas Gerais - $5^{\circ}$ Aproximação, Viçosa, p. 216, 1999.

SEMA, A.; MAITI, C. S.; SINGH A. K.; BENDANGSENGLA, A. DRIS Nutrient Norms for Pineapple on Alfisols of India. Journal of Plant Nutrition, New York, v. 33, n. 9, p.1384-1399, 2010.

SILVA, J. M.; FILLET SPOTO, M.H.; ONGARELLI, M.G.;FUMI SASAKI, F.; SAAVEDRA DEL AGUILA, J.; KLUGE, R.A. Uso do antioxidante 4-hexylresorcinol em abacaxi minimamente processado. Revista Iberoamericana de Tecnología Postcosecha, v. 8, n. 2, p.101-107, 2007. 
SILVA, D. F. da; PEGORARO, R. F.; MEDEIROS, A. C.; LOPES, P. A. P.; CARDOSO, M. M.; MAIA, V. M. Nitrogênio e densidade de plantio na avaliação econômica e qualidade de frutos de abacaxizeiro. Pesquisa Agropecuária Tropical, Goiânia, v. 45, n. 1, p. 39-45, 2015.

SPIRONELLO, A.; QUAGGIO, J. A.; TEIXEIRA, L. A. J.; FURLANI, P. R.; SIGRIST, J. M. M. Pineapple yield and fruit quality effected by npk fertilization in a tropical soil. Revista Brasileira de Fruticultura, Jaboticabal - SP, v. 26, n. 1, p. 155-159, 2004.

VILLAS BÔAS, R. L.; BOARETTO, A. E.; GODOY, L. J. G. de; FERNANDES, D. M. Recuperação do nitrogênio da uréia pelo milho: efeito da mistura com sulfato de amônio, da dose e do modo de aplicação. Bragantia, Campinas, v. 64, n. 2, p. 263272, 2005. 